\title{
Kant e Foucault: a priori, a priori histórico e genealogia
}

\author{
Kant and Foucault: a priori, historical a priori and genealogy
}

Felipe Luiz ${ }^{1}$

\author{
1 Mestrando em Filosofia pelo Programa de Pós-Graduação em Filosofia da Faculdade de Filosofia e Ciências/Universidade Estadual Paulista \\ "Júlio de Mesquita Filho" (FFC-UNESP/Marília). Bacharel em Filosofia pela FFC-UNESP/Marília. Brasil. \\ E-mail: gumapoldo51@yahoo.com.br Orcid: http://orcid.org/0000-0002-6446-0810
}

RESUMO: Nosso fito no presente trabalho é comparar duas concepções de a priori, uma de vertente kantiana, como consta na primeira parte da Crítica da razão pura, mais exatamente na Introdução desta mesma obra; a outra, tal qual elaborada por Foucault no livro As palavras e as coisas, sob o nome de a priori histórico e articular isto com a questão da genealogia, tal como aparecerá nos trabalhos de maturidade de Foucault, isto é, em seus trabalhos das décadas de setenta e oitenta. Para tanto, lançaremos mão de obras dos dois autores e de alguns comentadores que abordam o tema, sem pretender, no entanto, esgotar o assunto, ou seja, lançando uma pista de pesquisa.

Palavras-chave: A priori. A priori histórico. Genealogia.

ABSTRACT: Our objective in this work is to compare two conceptions of a priori, one Kantian, as it is the first part of the Critic of Pure Reason, exactly speaking, in the Introduction of this work; on the other hand, the concept of historical a priori, as Foucault have theorized in his book The Order of things, articulating that with the question of genealogy, in the way Foucault thought it in his later thought, that is, in the works of the 70's. In order to do that, we will utilize works of these two author and of some commentators who approach this theme, but without the pretension to deplete the controversy.

Keywords: A priori. Historical a priori. Genealogy.

\section{Introdução}

É muito comum que se analise Foucault sobre um viés eminentemente nietzscheano. Foucault teria descoberto o filósofo alemão nas praias da Itália, num distante dia da década de 50, quando passava férias na companhia de amigos. Até então, as preocupações de Foucault oscilavam em torno do debate premente na França, indo em direção a outros pensadores e correntes filosóficas. A fenomenologia existencial ou não—-, o marxismo, o hegelianismo, a psicanálise, talvez um estruturalismo ainda imberbe na pena de Dumézil. Foucault se interessava, quando de então, por problemáticas típicas da terra gaulesa, país este que fora sede do cartesianismo e do espiritualismo, indicando a centralidade que as reflexões sobre o cogito possuíam naquelas paragens. Em seus livros da década de 60 as referências a Nietzsche são muitas, como na História da loucura e n'As palavras e as coisas. Além disso, Foucault contribuiu na organização das obras completas de Nietzsche na França, o que ajudou a criar uma ideia de um filósofo profundamente nietzscheano, ideia esta cristalizada quando ele, já nos 70, lança textos de exegese de Nietzsche, pondo lenha na aura de seu nitezscheanismo redivivo. Isto não quer dizer que Foucault fosse insensível ao restante da filosofia ou que a desconhecesse; somente que ele tinha uma predileção muito clara pelo filólogofilósofo.

Alves (2007) descreve os efeitos que teve na França a publicação de um texto assinado como Mau- 
rice Florence, na verdade Foucault ele mesmo, se escondendo nas sombras de um pseudônimo, onde este se descrevia como um kantiano, indo contra o mainstream acadêmico francês e a opinião do público em geral. A olhar mais de perto, talvez não devesse causar tanta surpresa. N'As palavras e as coisas, Foucault concede um papel todo central à filosofia de Kant na edificação do saber moderno, o enxergando, mesmo, como limiar da modernidade, demiurgo de um pensamento que permitiu não só as ciências humanas, como determinou toda a reflexão filosófica hodierna.

O mesmo Alves nos fornece algumas indicações desta ligação entre Foucault e Kant, e é nessa pista que trabalhamos, aprofundando algumas indicações de Alves, ao intentar dar seguimento ao debate. Assim, buscaremos expor, um tanto quanto fora do nosso quinhão, algumas características da filosofia kantiana, a fim de compará-la com o pensamento de Foucault, seja aquele arqueológico, seja o genealógico, intentando mostrar semelhanças e similitudes. Não sendo nosso fito, não nos aprofundaremos nas minúcias da exegese da obra de Foucault, deixando isto para outros trabalhos.

Além da pista de Alves, outra fonte que pode nos interessar é o verbete "Kant" no Vocabulario Foucault, de Edgardo Castro (2004), o qual se debruçou sobre os escritos de Foucault e indica todas as referências a Kant que o filósofo francês fez do prussiano. Há de nos servir como introito. O estudioso argentino aponta que há uma relação de ruptura e continuidade entre Foucault e o pensador das Luzes. Ruptura porque Foucault, em uma linha nietzscheana, não aceita a existência de um transcendental, tampouco é um humanista como Kant, muito menos compartilha os fundamentos da ética deste. Castro aponta, como também o faz Schneider (s/d), como a arqueologia foucaultiana foi inspirada em Kant. Outra relação possível seria a análise que o mestre francês faz da indagação kantiana contida no texto Beantwortung der Frage: $W$ as ist die Aufklärung, sendo que a interpretação de Foucault normalmente é encarada como delimitando sua famosa noção de ontologia do presente.

Nos passos de Alves e Castro, será nosso fito encarar como Foucault pode, de fato, ser encarado como um kantiano, posto que ambos se debruçam sobre um mesmo tipo de análise, a das condições, históricas e de possibilidade formal, respectivamente. Passando pela arqueologia e genealogia, mostraremos como, malgrado as muitas diferenças que possam existir, os dois métodos se comunicam na analítica dessas condições.

\section{Kant e o a priori}

O problema de Kant na Crítica envolve um debate de múltiplo aspecto. Kant está em diálogo com a ciência de seu tempo, bem como, especialmente, com a metafísica racionalista e as obras empiristas que avaliavam esta discussão. Neste mar de ideias, pode-se dizer que a Crítica é o fecho de um debate, conciliando posições racionalistas e empiristas, na tentativa de alçar a argumentação a um outro nível. Avaliando os progressos das ciências de então, Kant se perguntava por que estes progressos não se davam na Metafísica, onde cada sistema negava os predecessores, afirmando-se como dono da verdade, sem um real sentido de continuidade; um panorama muito distante da lógica e da matemática dezoitistas, que, desde da Antiguidade teriam achado o caminho seguro da ciência, e da física, que encontrara esta mesma via a partir dos trabalhos de Newton. É nesse debate espinhoso que Kant pretende entrar, e onde se valerá do conceito de a priori, que ele define logo no princípio da Crítica, que é o que mais nos toca neste pequeno escrito. Não discutiremos se a Crítica contém uma discussão epistemológica ou ontológica, como faz BONACCINI (2017), muito além de nosso escopo, nos limitando aos primeiros capítulos da Crítica.

Para Kant, todo conhecimento começa com a experiência, na seguinte ordem: os objetos empíricos 
são percebidos pelos sentidos, estas impressões são trabalhadas por nossas faculdades intelectuais, transformando-as em experiência. Temporalmente falando, esta é a origem de todos os conhecimentos. Isto, contudo, não quer dizer que todo conhecimento seja empírico, posto que há determinados conhecimentos não dependentes da experiência, que Kant chama de conhecimentos a priori. Os juízos a priori são "aqueles que não dependem desta ou daquela experiência, mas aqueles em que se verifica absoluta indpendência de toda e qualquer experiência” (KANT, 1994, p. 37), tais como aqueles da matemática e da lógica puras.

Para Kant, todo proposição necessária é sempre a priori, bem como os conhecimentos de verdadeira universalidade, não aqueles indutivos, advindos da experiência. Este tipo de conhecimento a priori seria proveniente, diz Kant, de uma faculdade do conhecimento também a priori. Como exemplos de conhecimento a priori Kant nos oferece o conceito de espaço, sem o qual nenhuma experiência pode ser pensada, e o conceito de substância, do qual depende todo material empírico. "Com efeito, todo o conhecimento que possui um fundamento a priori anuncia-se pela exigência de ser absolutamente necessário” (KANT, 1994, p. 7).

Na sequência, Kant introduz a distinção entre juízos sintéticos (que adicionam um predicado ao sujeito) e juízos analíticos (nos quais o predicado está contido no sujeito). Vê-se que estes últimos não podem ser fundados na experiência, conquanto aqueles devem ser fundados nesta. O problema da Metafísica seria o de querer obter juízos sintéticos a priori, portanto, aumentar nossos conhecimentos sem o recurso à experiência como pedra de toque. Os juízos da matemática seriam juízos sintéticos, bem como os da geometria, além da física, que também conteria juízos sintéticos a priori. "O verdadeiro problema da razão pura está contido na seguinte pergunta: como são possíveis os juízos sintéticos a prior??” (KANT, 1994, p. 49). Portanto, sua resolução toca não somente a Metafísica, como também a Matemática e a Física puras.

Kant envereda também pelos caminhos da análise das possibilidades da razão conhecer a priori. Faz também uma distinção: se a razão permite-nos conhecer a priori, “a razão pura contém os princípios para conhecer algo absolutamente a priori” (KANT, 1994, p. 53). Não entraremos no mérito da distinção entre a priori e absolutamente a priori, posto que tal debate redundaria em ampla análise da Crítica, algo que ultrapassa nossos objetivos.

Conforme o Dicionário Kant. "Nos juízos sintéticos a priori estão compreendidos dois elementos, a saber, as intuições a priori puras e os conceitos a priori puros" (CAGYLL, 2000, p. 211). A fim de mostrar a possiblidade desses conceitos, é necessário ao filósofo de Königsberg mostrar a existência de conceitos e intuições a priori passíveis de serem sintetizados. Das formas a priori da sensibilidade (tempo e espaço, que operam o material bruto fornecido pelas sensações) é possível deduzir variados conhecimento sintéticos. Mas, "por si mesmas, não podem propiciar as condições de possibilidade para juízos sintéticos a priori; isso só pode acontecer quando eles estão alinhados com conceitos a prior”" (CAGYLL, 200, p. 211), que são próprios ao entendimento. As categorias a priori do entendimento também não podem fornecer a possiblidade dos juízos sintéticos a priori, visto que é impossível das meras categorias a priori derivar qualquer conhecimento. Daí que Kant tome como errôneas as tentativas da ontologia. Aos juízos sintéticos a priori cumpre concertar tanto os elementos das formas a priori da sensibilidade quanto das categorias do entendimento, cobrindo tudo aquilo que pode ser revelado a priori na intuição correspondente. Ou seja, este tipo de juízo somente é possível em experiências possíveis ou na possibilidade de qualquer experiência. "O que isso significa é que as condições de possibilidade de juízos sintéticos a priori compreendem princípios que unem elementos conceituais e intuitivos, e que são pressupostos por distintos atos de juízos sintéticos $a$ prior" (CAGYLL, 2000, p. 211). Ou seja, da união entre as condições formais da intuição a priori, com a 
síntese da imaginação e sua conformidade na apercepção transcendental, seria dado um tipo de saber acerca da experiência enquanto tal. Na relação entre estes termos reside, pois, a possiblidade dos juízos sintéticos a priori. Como diz Kant "a possibilidade da experiência é que confere realidade objetiva a todos os nossos conhecimentos a priori” (KANT, 1994, p. 200).

Ou seja, é analisando as condições de possiblidade da experiência, a qual, ao mesmo tempo, dá as condições de possiblidade dos objetos da experiência, é possível se fundamentar os juízos sintéticos a priori. A indagação de Kant é, nessa feita, uma indagação das condições da experiência; não desta ou daquela experiência, como fica patente na própria definição do a priori, mas de qualquer experiência possível, delimitando o que pode ou não pode ser dado a conhecer. A questão das possiblidades, das condições, é a grande questão da epistemologia crítica.

\section{Foucault, genealogia e o a priori histórico}

É no âmbito da pesquisa arqueológica que o filósofo francês introduz o a priori histórico, mais exatamente no livro As palavras e as coisas. A arqueologia é o método que Foucault se vale no primeiro tempo de suas reflexões, avaliando o campo do saber enquanto discurso e suas mutações. Analisando o surgimento das Ciências Humanas, entre fins do século XVIII e princípios do XIX, Foucault descobre a historicidade do saber e como a figura do homem, enquanto sujeito e objeto de saber são recentes.

Um conceito central deste livro é o de épistémè, que indica o não pensado do saber, quer dizer, aquilo que determina sujeitos, temas, conceitos, disciplinas. Cada época possui sua própria episteme, sua própria organização do saber, de modo que o saber possui uma história e uma geografia. Foucault nos convida à reflexão ao expor uma enciclopédia chinesa que distingue os animais, em uma taxinomia científica, em, por exemplo, aqueles que podem ser pintados com um pincel de pêlo de camelo muito fino, e aqueles pertencentes ao imperador. Esta distinção, completamente alienígena à nossa racionalidade, torna patente que o saber passa por múltiplas transformações, engendrando elaborações completamente díspares. Foucault distingue três épistémès no Ocidente desde o século XVI. A primeira, própria ao Renascimento, foi organizada em torno da noção de semelhança; a segunda, no que ele chama da Idade Clássica (séculos XVIIXVIII), se organiza em torno da representação; e por fim, a nossa, pensada em torno da noção de finitude, onde aparece o homem como sujeito e objeto de saber.

Foucault introduz também a noção de a priori histórico: ele é aquilo que

numa dada época recorta na experiência um campo de saber possível, define o modo de ser dos objetos que aparecem, arma o olhar cotidiano de poderes teóricos e define as condições em que se pode sustentar sobre as coisas um discurso reconhecido como verdadeiro (FOUCAULT, 1985, p. 173)

Há outras utilizações do termo a priori no texto foucaultiano. Por exemplo: comentado a passagem da épistémè clássica para a moderna Foucault afirma que a consituição da história do saber só (...) "pode ser feita a partir do que lhe foi contemporâneo e não certamente em termos de influência recíproca, mas em termos de condição e de a priori constituídos no tempo" (FOUCAULT, 1985, p. 223).

Outra aparição do termo a priori se dá exatamente quando Foucault está comentando Kant. Analisando as mudanças da épistémè clássica (representação) para a moderna, Foucault aponta que a filosofia crítica se põe a analisar a relação das representações entre si. Para Foucault, contudo, Kant não pensa a representação no plano da representação, antes as pensando em termos das condições que a tornam uni- 
versalmente válidas. Somente empiricidades podem se fundar na representação e em seus conteúdos. "Qualquer outra ligação, para ser universal, deve fundar-se para além de toda experiência, no a priori que a torna possível” (FOUCAULT, 1985, p. 257).

Vê-se, portanto, que entre épistémè e a priori historico as relações são evidentes, mas há sutis diferenças. A epistemê trabalha definindo as disciplinas do saber, enquanto que o a priori define aquilo que póde ser experimentado em dada formação. Mas a epistemê é mais geral: uma epistemê possui um a priori, não o contrário Ambos os conceitos fazem referência, no entanto, àquilo que podemos conhecer, quer dizer, trabalham definindo as condições de uma experiência possível historicamente em dada formação social.

É comum que se aponte que há uma ruptura, ou uma mudança em Foucault em meados da década de 70, mudança esta sinalizada pelo seu discurso inaugural no Collège de France, e materializada em Vigiar e Punir. Este détour é, sobretudo, metodológico, posto que implica o abandono ou mitigação de um método, o arqueológico, em benefício de um novo, o genealógico. O alcande destas mudanças, se se deve cindir Foucault em torno dela, e questões similares, não serão nosso objeto; tal qual o arqueólogo do saber, por ora apenas constamos uma diferença, uma alteração que se passou.

A arqueologia foi se delineando ao longo de toda a década de 1960. Já na História da loucura, o termo aparece diversas vezes. Durante todo o período, Foucault a purifica até chegar nos cimos de sua definição, detalhada e muito rica filosoficamente, na Archéologie du savoir (1969). Em poucas palavras, escassas demais para conceituar uma problemática que ocuparia tomos, podemos expor que a arqueologia, que é de origem kantiana, conforme indicado alhures, é a investigação do arquivo de uma sociedade em dado período, sempre diferente do nosso, posto que, segundo Foucault, a análise arqueológica é post-festum. O arquivo é a lei do que pode ser enunciado, quer dizer, define as condições de qualquer enunciação possível, mas não à moda kantiana, posto que não se trata de definir condições transcendentais de enunciabilidade, mas condições arqueológica, isto é, no nível da função enunciativa, que permite as formações discursivas. Em bom português, significa que a arqueologia estuda o que é possível, em cada época e sociedade, ser dito, escrito, pronunciado, e ser levado a sério — os serious speech acts, como dizem Rabinow e Dreyfus (1982). Mas aqui o campo do enunciado é tomado de forma ensimesmada, ou seja, isolado das práticas não discursivas, em seu limiar. Devem-se explicar as condições e as mudanças de uma formação discursiva como se esta se constituísse em um campo próprio, sem fazer referência aos fatos históricos ou políticos, para que não sirvam como uma espécie de arché do discurso, algo que Foucault evita. Trata-se de tomar o discurso pelo meio, de entendê-lo como a erva — procedimento próprio ao pós-estruturalismo, como bem o define Deleuze (1996).

A genealogia, a seu turno, aparece como método de análise na década de 1970, indicando novos rumos para a pesquisa. De origem nietzscheana, é sobremaneira em um texto, contraditoriamente, um necrológio a Jean Hyppolite, hegeliano notório, que Foucault vai se debruçar sobre a genealogia. Neste texto, Foucault aponta que a genealogia, tal qual aparece em Nietzsche, é um método documental de análise histórica que busca desconstruir as unidades, mostrando como determinadas relações de força contribuiram para a emergência de um corpo (um caráter, uma característica). A genealogia se opõe às histórias que buscam derivar o conjunto do processo histórico de uma essência idealizada, que se repete na idealidade de um passado reconstruído; ao contrário, o genealogista desdobra lutas, processos de dominação, acasos, para mostrar que o presente é o fruto sempre belicoso de lutas pregressas. A genealogia disssocia, 
portanto, através da explicitação de uma proveniência, na qual se marcam a emergência de um corpo.

As metáforas bélicas se sucedem. Foucault diz que "o que se encontra no começo histórico das coisas não é a identidade ainda preservada da origem — é a discórdia entre as coisas, o disparate” (FOUCAULT, 2007b, p. 18). Acrescenta que "é preciso saber reconhecer os acontecimentos da história, seus abalos, suas surpresas, as vacilantes vitórias, as derrotas mal digeridas” (FOUCAULT, 2007b, p. 19), e neste ínterim se situar enquanto genealogista. A genealogia introduz, no campo do discurso, a problemática do poder, ligando-o às disputas políticas e aos entremeios das relações de força.

Vê-se assim que nossas dificuldades aumentam. Ora, se é mister evitar a pesquisa de identidade, qualificada por Foucault de metafísica, como elaborar posições mais generalistas? Salta aos olhos, no referido texto, que o devir devém em uma correlação de forças — mas dizê-lo é incorrer em uma proposição metafísica, posto que tal afirmação não pode ser documentada: como documentar o devir todo, o conjunto do que devém? Esta armadilha foucaultiana, nos conduzindo a sempre elaborar estudos parciais, pode ser comparada com aquela famosa expressão de Wittgenstein no Tractatus, segundo a qual se deve jogar fora a escada depois de tê-la escalado (WITTGENSTEIN, 2017, p. 261). Para prosseguir, portanto, devemos abandonar Foucault, deixar de ser foucaultianos, caso queiramos generalizar.

Parece que, para Foucault, o devir sempre devém em uma correlação de forças. Não à toa, ele dedicará um de seus cursos no Collège de France a estudar a origem situada de um discurso que compreende a história em termos de guerra, precedendo em dois séculos a analítica da luta de classes (FOUCAULT, 1999). Neste mesmo curso, contudo, Foucault se recusa a dar um sentido de unidade ao método genealógico, talvez pelas razões apontadas, talvez pelo "cretinismo" de considerar que um a teoria totalitária conduz a regimes também totalitários ${ }^{1}$. A análise mais cuidadosa de seus textos pode revelar estes aspectos, o que nos dá pistas para uma pesquisa futura.

Por ora, basta marcar esta recusa de Foucault em fornecer uma teoria unitária do devir, talvez tendo por fundo a recusa em oferecer uma ontologia no sentido mais forte do termo, reputada de metafísica; ou senão porque ele se contentou em constituir uma ontologia histórica, como quer Ester Díaz (1995). É bom marcar, também, que em um dos textos arqueológicos que Foucault aborda a questão da história, o prefácio à Arqueologia do saber, ele considera que este problema do devir estava superado, em benefício da problemática do documento, a qual, em seu entender, emergia como o principal problema do campo da história. Ao invés, portanto, de uma teoria do devir, de totalizações, "flechas genealógicas", que, ao contrário, impeçam esta teoria geral.

\section{Conclusões}

Quais relações podemos tecer entre arqueologia e genealogia? A primeira parece elaborar uma teoria geral, que engloba todas as produções de uma época, intentando fornecer, já no elemento do arquivo, uma teoria geral contingente histórica do dizível. A genealogia parece, exatamente, negar este tipo de teoria que Foucault quis elaborar, desfazendo as unidades e introduzindo as relações de força no campo discursivo. Daí também que se possa fazer paralelos entre o Foucault arqueológico de As palavras e as coisas e o a priori kantiano, conquanto este paralelo parece não se sustentar quanto ao Foucault da genealogia.

Mas parece haver unidade entre estas produções tão distintas. Em todos os casos trata-se de refe-

\footnotetext{
1 Como aponta José Paulo Netto: NETTO, J. P.; Posfácio in COUTINHO, C.N.; O estruturalismo e a miséria da razão, SP: Expressão Popular, 2010, $2^{\mathrm{a}}$ ed.
} 
rências à análise de uma condição. Quer dizer, tanto Kant quanto Foucault estão indagando pelas condições de um saber, no caso de Kant, os juízos sintéticos a priori, no caso da arqueologia, o saber das Ciências Humanas em sua possibilidade discursiva, no caso da genealogia uma indagação sobre o que permite o presente em um gradil de forças em luta, uma indagação sobre tudo quanto possibilitou o presente, naquilo que Foucault chama de ontologia do presente, termo que aparece exatamente em um texto no qual o filósofo gaulês está comentando Kant (FOUCAULT, 1994, p. 679). Assim, haveria um kantismo em Foucault, talvez sutil, mas que pode ser encontrado ao longo de sua obra (ALVES, 2007).

Há diferenças. Kant busca as condições formais de todo conhecimento possível, o que está no cerne da filosofia transcendental. Já Foucault se debruça sobre as condições históricas, datáveis, documentadas. Para ser exato, se levarmos a sério os critérios de Foucault, Kant seria um metafísico: busca na idealidade uma origem arquetípica, como descrevemos, ainda que sob a capa da pesquisa transcendental. Já a genealogia ou a arqueologia, por serem fortemente históricas, não seriam metafísicas, estando ligadas a um projeto mais geral de uma ontologia do presente.

Então, podemos dizer que se trata de duas filosofias que analisam as condições do saber, uma à moda metafísica, mesmo que disfarçada; a outra, que se desfez dos sonhos da metafísica, e se pauta na historicidade. Mas ambas, de mãos dadas, pesquisando as condições pelas quais se pode saber aquilo que se pode saber. Se trata de pesquisas complementares ou, ao contrário, se anulam? A questão é bastante

pertinente. À primeira vista, parece se tratar de posturas contraditórias; mas, talvez vistas mais de perto, podem implicar uma continuidade subterrânea. Somente uma análise mais detida, e futura, pode respondê-lo.

\section{Bibliografia}

ALVES, A. A crítica de ponta-cabeça: sobre a significação de Kant no pensamento de Foucault, São Paulo: TRANS/FORM/AÇÃO, V 30 (1), 2007

BONACCINI, J.; Analítica e Ontologia: sobre a teoria kantiana dos objetos a priori in DOS SANTOS, L. R. et ali; Kant e o a priori, SP: Cultura Acadêmica, 2017

CAYGILL, H. Dicionário Kant. Tradução Álvaro Cabral; revisão técnica Valério Rohden, Rio de Janeiro: Jorge Zahar Editores, 2000

DELEUZE, G. PARNET, C. Dialogues, Paris: Flammarion, 1996

DÍAZ, E. La Filosofia de Michel Foucault. Buenos Aires: Biblos, 1995, 187 p

DREYFUS, H. L. RABINOW, P. Michel Foucault: Beyond Structuralism and hermeneutics, Chicago: University of Chicago Press, 1982

EBELING, K. ALTEKAMP, S. Die Aktualität des Archäologischen in Wissenschaft, Medien und Künsten. s/l: Fischer Taschenbuch Verlag, s/d

FOUCAULT, M. A arqueologia do saber. RJ: Forense, 2007a, $7^{\text {a }}$ ed.

. As palavras e as coisas. SP:Martins Fontes, 1985, $3^{\mathrm{a}}$ ed.

. Dits et écrits IV (1980-1988). Paris: Gallimard, 1994

. É preciso defender a sociedade. SP: Martins Fontes, 1999.

. Microfísica do poder. RJ: Graal, 2007b 
KANT, I. Crítica da Razão Pura. Lisboa: Calouste Gulbenkian, $3^{a}$ ed., 1994

DOS SANTOS, L. R. et ali. Kant e o a priori. SP: Cultura Acadêmica, 2017

RAINSBOROUGH, M. Thema and variation: Foucault's historical apriority as criticism of Kant's concept of a priori. In DOS SANTOS, L. R. et ali. Kant e o a priori. SP: Cultura Acadêmica, 2017

SCHNEIDER, U. J. Philosophische Archäologie und Archäologie der Philosophie: Kant und Foucault in EBELING, K. ALTEKAMP, S. Die Aktualität des Archäologischen in Wissenschaft, Medien und Künsten. s/l: Fischer Taschenbuch Verlag, s/d

WITTGENSTEIN, L. Tractatus lógico-philosophicus. SP: EDUSP, 2017, $3^{a}$ ed.

Artigo recebido em: 09 de dezembro de 2019

Artigo aceito em: 27 de fevereiro de 2020 